FSS

Rui, J. R., Cui, X., Xu, Q., \& Yu, N. (2021). How public interactions via WeChat moments predict the emotional well-being of Chinese seniors and emerging seniors: The moderating roles of perceived self-network discrepancy and age. Cyberpsychology: Journal of Psychosocial Research on Cyberspace, 15(3), Article 2.

https://doi.org/10.5817/CP2021-3-2

\title{
How Public Interactions via WeChat Moments Predict the Emotional Well-Being of Chinese Seniors and Emerging Seniors: The Moderating Roles of Perceived Self-Network Discrepancy and Age
}

\author{
Jian R. Rui ${ }^{1}$, Xi Cui ${ }^{2}$, Qian $\mathrm{Xu}^{3}$, \& Nan $\mathrm{Yu}^{4}$ \\ ${ }^{1}$ South China University of Technology, Guangzhou, China \\ ${ }^{2}$ College of Charleston, Charleston, South Carolina, USA \\ ${ }^{3}$ Elon University, Elon, North Carolina, USA \\ ${ }^{4}$ University of Central Florida, Orlando, Florida, USA
}

\begin{abstract}
The present study examined how engaging in public interactions via WeChat Moments (i.e., interactions all WeChat contacts can access) was related to the emotional well-being of Chinese seniors and emerging seniors (50 years or older). Results of an online survey $(N=506)$ demonstrated that perceived educational self-network discrepancy of WeChat network moderated the relationship between public interactions and emotional well-being such that only at a high level of perceived educational self-network discrepancy public interactions exhibited a significant negative relationship with emotional well-being. Additionally, the interaction between public interactions and perceived educational/social class self-network discrepancy on emotional well-being was further moderated by the participants' age. Specifically, the relationship between public interactions and emotional well-being was only significant and negative at high levels of perceived educational/social class self-network discrepancy among older Chinese seniors and emerging seniors, whereas this relationship was not significant at any level of perceived educational/social class self-network discrepancy among their younger counterparts. This study develops the scholarship on social networking services and well-being by suggesting that the responses one receives from their online network can have a critical impact on their well-being and provides implications about extending socioemotional selectivity theory.
\end{abstract}

Keywords: Emotional well-being; social networking service; socioemotional selectivity theory; online network

\section{Introduction}

Senior citizens and emerging seniors are traditionally considered digitally disadvantaged, but now they are increasingly active on social networking services ${ }^{1}$ (SNSs) through mobile devices (Y. Zhang \& Leung, 2014). A Pew report shows that 37\% of Americans aged 65 and older used at least one SNS (Smith \& Anderson, 2018). The extant scholarship has illustrated how seniors and emerging seniors use SNSs prevalent in North America and Europe such as Facebook and Twitter (Chang et al., 2015; Jung \& Sundar, 2016; Pfeil et al., 2009). However, equally important but understudied is the use of native SNSs in other regions. 
Up till the last quarter of 2019, WeChat had over 1.165 billion active monthly users in China (Statista, 2019). Although the majority of WeChat users is still younger adults, seniors and emerging seniors have become increasingly active (Hersey, 2017). For example, the number of active WeChat users over 55 increased from 7.68 million in 2016 to 50 million in 2017 (Xinhua, 2018). They spent around 1.37 hours on WeChat every day and had 104 WeChat friends on average (Xinhua, 2018). As SNS use could affect individuals' well-being (Tromholt, 2016; Utz \& Breuer, 2017), it is important to understand how WeChat use affects the well-being of Chinese seniors and emerging seniors.

Prior research has provided mixed results about the relationship between SNS use and well-being (see Marino et al., 2018, for a review). One possible reason is that many studies focus on the overall usage of SNSs (e.g., Brooks, 2015). However, SNSs allow for a mix of communication activities, such as one-to-one interactions, group chats, and public self-disclosure to the entire network, which can cause different relational and psychological outcomes (Burke et al., 2011; Escobar-Viera et al., 2018). Therefore, our investigation focuses on only one type of communication activities through SNSs --- public interactions through WeChat Moments ${ }^{2}$, where WeChat users can share text-based posts, photos, and videos publicly, similar to Facebook News Feed. We defined public interactions as communication activities that are accessible to one's entire WeChat network. Additionally, prior research has explained how communicating publicly with the entire network may affect emotional well-being through the lens of social support and catharsis (Bayer et al., 2018; Bazarova et al., 2015; Choi \& Bazarova, 2015; Luo \& Hancock, 2020). The present research aims to extend this scholarship by considering the moderation effects of perceived self-network discrepancy and individuals' age.

First, contemporary online networks are typically composed of audience members of diverse backgrounds (Hampton et al., 2011; Lee et al., 2014), yet SNSs collapse these audience segments into one common space by enabling users to communicate publicly and simultaneously with their entire online network (Davis \& Jurgenson, 2014; Marwick \& boyd, 2011). Consequently, individuals are often exposed to different opinions and interact with people holding different values (Pearce \& Vitak, 2016; Walden, 2016). Research shows that these cross-cutting interactions may not be able to change individuals' attitude (Bail et al., 2018; Catapano et al., 2019) but can increase the chance of conflicts (Binder et al., 2009; John \& Dvir-Gvirsman, 2015). Therefore, engaging in public interactions may predict emotional well-being positively at low levels of cross-cutting communication, whereas this relationship may be negative at high levels of cross-cutting communication. We propose perceived self-network discrepancy in one's WeChat network, defined as the extent to which one's value is perceived differently from their WeChat contacts. We argue that perceived self-network discrepancy may indicate one's perception of the level of cross-cutting communication they have experienced and thereby should moderate the relationship between public interactions and emotional well-being.

Furthermore, socioemotional selectivity theory (SST) maintains that people prioritize different goals depending on their perception of future time, and they are motivated to maximize well-being when they perceive their future time is limited (Carstensen, 2006). Empirical research on SST shows that age influences how individuals respond to conflicts (see Carstensen, 2006 for a review). Thus, although frequent cross-cutting communication via WeChat Moments can trigger negative emotions and thereby cause a decline in emotional well-being, users' responses to these WeChat posts expressing different opinions likely vary depending on their age (Carstensen, 2006; Levenson et al., 1993). Hence, the second goal of the present study is to test the possible three-way interaction effect between public interactions, perceived self-network discrepancy, and age on the emotional well-being of Chinese seniors and emerging seniors.

We first review the scholarship on WeChat and conceptualize public interactions as an example of masspersonal communication. Next, drawing on context collapse, we discuss how perceived self-network discrepancy may moderate the relationship between public interactions and emotional well-being. Finally, based on SST, we explain how this two-way interaction effect may be further moderated by the age of Chinese seniors and emerging seniors.

\section{WeChat and Public Interactions}

As a result of its popularity in China, there have been a growing number of empirical studies on WeChat, such as what motivates individuals to use WeChat (Lien \& Cao, 2014; L. Zhang \& Jung, 2018), how WeChat affects youths' 
subjective well-being (Wen et al., 2016), and how older adults engage in civic participation through WeChat (Guo, 2017). Previous studies also explicated what motivates users to "like" WeChat posts (Gan, 2017) and how individuals use public accounts, where they could read and share articles (Wei et al., 2018).

Among the various communication activities that WeChat affords, public interactions via Moments have not received sufficient scholarly attention. Public interactions represent a new communication mode that differs from interpersonal communication and mass communication. On the one hand, public interactions are visible to one's entire SNS network unless certain contacts are blocked. This high visibility could invite multiple users to join one single conversation. Thus, public interactions are different from interpersonal communication, which is typically conceptualized as one-on-one communication (O'Sullivan, 1999). On the other hand, public interactions are not the same as mass communication as feedback is typically unavailable via mass communication (O'Sullivan, 1999).

Litt (2012) argued that when SNS users display public posts to a wide audience, they tend to target their posts at specific segments of their social network. They use their knowledge of those contacts to construct posts (Litt, 2012). Consequently, public interactions via SNSs may be targeted at a mass audience but the content can be highly personal (Litt, 2012; O'Sullivan \& Carr, 2018). O'Sullivan and Carr (2018) termed this type of communication as masspersonal communication.

The present study focuses exclusively on public interactions because as argued earlier, different types of communication activities may account for the mixed results about the relationship between SNS use and wellbeing (Burke et al., 2011; Escobar-Viera et al., 2018). Thus, research on one type of SNS activities may reveal more precise and nuanced results of the effect of SNSs on well-being.

Additionally, prior research revealed that public self-disclosure via SNSs can be associated with emotional wellbeing positively. For example, Bayer et al. (2018) found that sharing statuses, wall posts, and comments via Facebook News Feed was positively associated with positive affect in the next 10 minutes, which was one component of emotional well-being (Fredrickson \& Joiner, 2002). Choi and Bazarova (2015) found that disclosing positive events publicly on Facebook was related to emotional well-being positively. Two explanations may account for these findings. The first lies in the cathartic effect of self-disclosure (Derlaga \& Berg, 1987). Additionally, individuals may receive social support from their SNS contacts (Luo \& Hancock, 2020). Examples of this type of social support include capitalization and recognition (Bazarova et al., 2015; Choi \& Bazarova, 2015). This perspective which centers on social support suggests that how individuals' SNS contacts respond to public interactions may play a critical role in the effect of public interactions on emotional well-being. In the present study, we extend this line of research through the lens of cross-cutting communication.

\section{Perceived Self-Network Discrepancy}

SNSs allow users to take advantage of its high visibility to communicate simultaneously with a large audience. However, SNS networks have become increasingly diverse such that one's SNS network is typically composed of people with different values (Lee et al., 2014; Pearce \& Vitak, 2016), jobs (Hampton et al., 201), or social relations (Rui \& Stefanone, 2013; Xu et al., 2013). When these diverse audience segments are collapsed into one common space, individuals inevitably engage in cross-cutting communication, for instance, being exposed to opinions they do not approve or interacting with people holding different values (Binder et al., 2009; Pearce \& Vitak, 2016; Walden, 2016).

Prior research revealed that exposure to different opinions might not change individuals' opinion (Bail et al., 2018; Catapano et al., 2019). For instance, Bail and his colleagues (2018) manipulated Republicans' and Democrats' exposure by sending them tweets with opposing political views through bots. Their results provided empirical evidence on polarization such that Democrats became slightly more liberal and Republicans became substantially more conservative after exposure (Bail et al., 2018). Similarly, Catapano et al. (2019) found that asking individuals to take the perspective of the opposing party by generating counter-attitudinal arguments lowered the chance of attitude change. In addition, cross-cutting interactions with people holding different values tend to be less open and less expressive of positive emotions and affection (An et al., 2019), characterized by more disagreements and conflicts (Binder et al., 2009; John \& Dvir-Gvirsman, 2015). For instance, through an interview of Azerbaijani SNS users, Pearce and Vitak (2016) found that young adults in Azerbaijan often experienced conflicts when their 
conservative family or friends accessed their SNS posts. Similarly, Walden (2016) found that younger employees were aware that their older colleagues or supervisors could judge them negatively based on their SNS posts.

Therefore, whether public interactions may enhance or lower emotional well-being should depend on the level of cross-cutting communication that individuals have experienced. In the present study, we propose perceived selfnetwork discrepancy as a proxy for cross-cutting communication because individuals may evaluate the degree to which their value deviates from their WeChat contacts (i.e., self-network discrepancy) based on how often they are exposed to different opinions or interact with people holding different values on SNSs. Based on the literature reviewed above, if individuals think their value is close to most of their WeChat contacts, they might have engaged in lower levels of cross-cutting communication on WeChat. Therefore, when they engage in public interactions, they should be more often exposed to posts they approve and their public posts are less likely challenged. This experience could enhance their positive emotion and ultimately improve their emotional well-being. Conversely, if they think they hold different values compared to the majority of their SNS contacts, they may have engaged in high levels of cross-cutting communication on WeChat. Therefore, when they engage in public interactions, they should be exposed to posts they disapprove more frequently and even challenged by their SNS network members (John \& Dvir-Gvirsman, 2015; Pearce \& Vitak, 2016; Walden, 2016). Ultimately, these experiences could have a negative effect on their emotional well-being. Therefore,

H1. Perceived self-network discrepancy moderates the relationship between public interactions and emotional well-being such that engaging in public interactions predicts emotional well-being of Chinese seniors and emerging seniors negatively at high levels of perceived self-network discrepancy whereas engaging in public interactions predicts emotional well-being positively at low levels of perceived self-network discrepancy.

In summary, $\mathrm{H} 1$ predicts that individuals engaging in a high level of public interactions and reporting a high level of perceived self-network discrepancy are the most likely to experience conflicts on WeChat. However, as SST suggests, individuals may react to conflicts differently depending on the length of perceived remaining time (Carstensen, 2006). Thus, within this population that are the most likely to experience conflicts on WeChat, individuals may react differently depending on their perceived remaining time, discussed next.

\section{SST and the Potential Moderation Effect of Age}

SST maintains that one's primary goal depends on their perceptions of how much time they have left in the future (Carstensen, 2006). When individuals perceive open-ended time horizons, they tend to prioritize future-oriented goals (Carstensen, 2006), which encourage them to acquire knowledge and expand their network (Carstensen et al., 1999). Conversely, when individuals think their future time is limited, they tend to focus on present-oriented goals (Carstensen, 2006), which motivate them to regulate their emotions and maintain meaningful relationships to maximize well-being (Carstensen et al., 1999).

The extant research has provided a wide spectrum of empirical evidence that supports SST. For instance, compared to young adults, seniors' SNS networks are smaller but have more emotionally close contacts (Chang et al., 2015; Pfeil et al., 2009) because seniors think it is more important to keep connections that can maximize their well-being (Carstensen et al., 1999). Additionally, seniors were consistently found to experience negative emotions less frequently than young adults (Carstensen et al., 1995; Carstensen et al., 2000; Gross et al., 1997) because seniors are more driven to manage their emotions (Carstensen, 2006) through strategies like engaging in mutual activities and taking vacations (Levenson et al., 1993).

Although typical SST research compares seniors and youths (see Carstensen et al., 1999 for a review), the theory posits that individuals pursue different goals because they have different perceptions of the length of their future time (Carstensen, 2006). Thus, among seniors and emerging seniors, individuals may respond to events that could lower their emotional well-being differently depending on their age.

Recall $\mathrm{H} 1$ predicts that perceived self-network discrepancy may moderate the effect of public interactions on emotional well-being because the high level of perceived self-network discrepancy suggests more chances of conflicts (An et al., 2019; Davis \& Jurgenson, 2014; John \& Dvir-Gvirsman, 2015; Pearce \& Vitak, 2016; Walden, 2016). SST suggests that this moderation effect of perceived self-network discrepancy on the relationship between public 
interactions and emotional well-being may be further moderated by age (Carstensen, 2006). Among those who engage in high levels of public interactions with a network of high degrees of perceived self-network discrepancy, older individuals may be more motivated to maximize well-being (Carstensen, 2006) and hence more likely to alleviate their negative emotions through emotion regulation strategies (Levenson et al., 1993). Therefore, although they may have experienced conflicts derived from high levels of cross-cutting communication, their emotion may be affected less. In contrast, younger individuals who engage in high levels of public interactions with a network of high degrees of perceived self-network discrepancy may report lower emotional well-being because their emphasis on future-oriented goals might make them less motivated to regulate their emotions (Carstensen, 2006). Thus, when exposed to WeChat posts that express different opinions or interacting with people holding different values, they might be more affected by these frustrating experiences. In other words, the negative effect of public interactions on emotional well-being in a network of high degrees of perceived self-network discrepancy may be more pronounced among younger Chinese seniors and emerging seniors because of their declined motivation to maintain positive emotions, compared to their older counterparts (Carstensen, 2006). Hence, the two-way interaction between public interactions and self-network discrepancy on the emotional well-being of Chinese seniors and emerging seniors may be further moderated by their age.

H2. There is a three-way interaction effect between public interactions, self-network discrepancy, and age on the emotional well-being of Chinese seniors and emerging seniors such that the negative relationship between public interactions and emotional well-being at high levels of self-network discrepancy may only be significant among younger individuals.

\section{Method}

\section{Data Collection and Sample}

Although there is no clear definition of senior citizenship, it is usually associated with the retirement status (World Health Organization, 2018). The retirement age in China is 60 for men and 55 for women, and women in bluecollar jobs can even retire at 50 if they want (Ming, 2021). Thus, we defined Chinese seniors and emerging seniors as those who are 50 years or older to include those who are considered elderly and those who are about to enter the final stage of their life.

Participants were recruited through an exponential non-discriminative snowball sampling. Each author recruited eligible participants from their respective WeChat contact lists. After participants indicated their consent to participation, they were directed to the link of the questionnaire. The researchers also asked the participants to pass along the questionnaire to those within the age range in their own WeChat contact lists.

The data were collected in September 2016 during a period of four weeks. We received a total of 506 responses. The average age of this sample was $60.90(S D=6.51, \operatorname{Min}=50, \operatorname{Max}=78)$. The frequency of age distribution was listed as follow: 50-55 (23.7\%), 56-60 (26.8\%), 61-65 (22.7\%), 66-70 (20.5\%), 71-78 (6.3\%). There were more females $(64.5 \%)$ than males $(34.7 \%)$, with others not indicating their gender $(0.8 \%)$. The majority of the participants had a college degree $(60.6 \%)$, followed by high school degree (22.5\%), middle school degree $(8.5 \%)$, master's degree (6.5\%), elementary school degree or a lower education level (1.2\%), and unspecified (0.8\%). At the time of data collection, one third of the participants reported a monthly income of 3001-5000 RMB (about \$443.93-739.64), with $24.1 \%$ for a monthly income of 5001-7000 RMB (\$739.79-1035.50), 21.9\% for 1001-3000 RMB (\$148.08443.78), $10.7 \%$ for 9001 RMB or more (\$1331.50 or more), $7.9 \%$ for $7001-9000$ RMB (\$1035.64-1331.35), $1 \%$ for income less than $1000 \mathrm{RMB}$ ( $\$ 147.93$ or less), and $1.2 \%$ did not specify.

\section{Measures}

\section{Dependent Variables}

Emotional well-being was conceptualized as "the emotional quality of an individual's everyday experience" ( $p$. 16489, Kahneman \& Deaton, 2010) and operationalized as the presence of positive emotions and the absence of negative emotions (Fredrickson \& Joiner, 2002). Scales measuring emotional well-being vary in their length and the type of emotions included (N. G. Choi et al., 2014; Fredrickson \& Joiner, 2002; Jiang, 2017). We used the scale 
by N. G. Choi et al. (2014) because it is designed for seniors. We asked participants to indicate during the past week how often they experienced two positive emotions (cheerful, full of life) and two negative emotions (bored, upset) on a 5-point scale: 1 ) never, 2) rarely (once a week or less), 3) some days (2-4 days a week), 4) most days (56 days a week), and 5) every day (7 days a week). To compute emotional well-being, the scores of positive emotions (Cronbach's $a=.83, M=3.56, S D=1.04$ ) were averaged and then subtracted the average of negative emotions (Cronbach's $a=.76, M=1.73, S D=0.79)$. The score of emotional well-being ranged from -4 to $4(M=1.83, S D=$ 1.60).

\section{The Independent Variable and the Moderator}

We operationalized public interactions as the interactions through WeChat Moments which all WeChat contacts can access and measured this variable with four items: posting photos, updating text-based statuses, commenting on other users' photos, statuses, and reposts, and reposting articles. We asked participants to indicate how often they engaged in these activities on a 5-point scale: 1) very rarely or never, 2) rarely, 3) sometimes, 4) often, and 5) very often or always (Cronbach's $a=.68, M=2.73, S D=0.81$ ). We did not include liking others' WeChat posts because liking on WeChat is only visible to mutual friends of the poster and the person that initiates the liking, rather than the entire WeChat network. We did not include reposting friends' photos and statuses because this function is not available through WeChat Moments. Although the reliability of public interactions is slightly lower than .7, the widely used threshold, some research argued that Cronbach's a of .6-.7 is acceptable (Taber, 2018; Ursachi et al., 2015).

We operationalized perceived self-network discrepancy as perceived educational and social class self-network discrepancy with one's WeChat network because differences in educational level and social class are typically related to different values (Kohn, 1963). Additionally, although previous research suggests that political and ethnic differences can cause conflicts on SNSs (John \& Dvir-Gvirsman, 2015; Pearce \& Vitak, 2016), they may not apply to the present study. The political system in China has less tolerance for diverse political opinions, and approximately 91\% of Chinese population are Han, making China ethnically homogeneous (Kargbo, 2017). Thus, we only focus on perceived educational and social class self-network discrepancy. We measured perceived educational selfnetwork discrepancy by asking participants to estimate the proportion of their WeChat contacts that was different from their own educational levels on a 5-point scale: 1) only very few or almost no, 2) just a few, 3) probably half, 4) quite a number-over half, and 5$)$ most or all of their WeChat network $(M=2.68, S D=1.00)$. Perceived social class self-network discrepancy was measured on the same 5 -point scale $(M=2.62, S D=1.04)$.

\section{Control Variables}

Demographic variables, specifically sex $(0=$ male, $1=$ female $)$, education, and income were controlled. Age was treated as a control variable when $\mathrm{H} 1$ was tested and a moderator when $\mathrm{H} 2$ was tested.

We also controlled for retirement status $(0=$ not retired, $1=$ retired $)$ and co-living status $(0=$ not co-living, $1=$ coliving) which refers to whether our participants lived in the same city as their children because living in the same city provides more opportunities for family communication, which can improve their emotional well-being. At the time of data collection, $74.4 \%$ of our participants retired and $68.2 \%$ lived in the same city as their children.

Next, we controlled for WeChat network size because network size tends to be correlated with well-being, and we measured it by asking participants to report the number of contacts in their WeChat network $(M=139.73, S D=$ 106.72). Additionally, we controlled for life satisfaction and social integration, which were important indicators of one's well-being (Diener et al., 1985; Keyes, 1998). Life satisfaction was measured using a 5-item scale by Diener et al. (1985). Sample items include "in most ways my life is close to my ideal" (Cronbach's a $=.84, M=3.40, S D=$ 0.78). Social integration was measured using a 6-item scale by Keyes (1998), which indicates the extent to which individuals were accepted by their social groups. Sample items state "I feel like I'm an important part of my community" (Cronbach's a = .76, $M=3.43, S D=0.62$ ). Both variables were measured on 5-point Likert scales. Table 1 presents descriptive statistics and bivariate correlations between the continuous variables mentioned above. 
Table 1. Descriptive Statistics and Zero-Order Correlations for Variables; Means (Standard Deviations) Presented Along the Diagonal.

\begin{tabular}{|c|c|c|c|c|c|c|c|}
\hline & $\begin{array}{c}\text { Public } \\
\text { interactions }\end{array}$ & $\begin{array}{c}\text { Perceived } \\
\text { educational } \\
\text { self-network } \\
\text { discrepancy }\end{array}$ & $\begin{array}{c}\text { Perceived } \\
\text { social class } \\
\text { self-network } \\
\text { discrepancy }\end{array}$ & Network size & $\begin{array}{l}\text { Emotional } \\
\text { well-being }\end{array}$ & $\begin{array}{c}\text { Life } \\
\text { satisfactio } \\
n\end{array}$ & $\begin{array}{c}\text { Social } \\
\text { integration }\end{array}$ \\
\hline $\begin{array}{l}\text { Public } \\
\text { interactions }\end{array}$ & $2.73(0.81)$ & $.14^{* *}$ & $.09^{*}$ & $.11^{*}$ & .04 & $.19^{\star \star \star}$ & $.26^{\star \star \star}$ \\
\hline $\begin{array}{l}\text { Perceived } \\
\text { educational } \\
\text { self-network } \\
\text { discrepancy }\end{array}$ & & $2.68(1.00)$ & $.49^{\star \star \star}$ & .002 & -.08 & .004 & .01 \\
\hline $\begin{array}{l}\text { Perceived } \\
\text { social class self- } \\
\text { network } \\
\text { discrepancy }\end{array}$ & & & $2.62(1.04)$ & .06 & $-.11^{*}$ & .01 & -.07 \\
\hline Network size & & & & $139.73(106.72)$ & .02 & .06 & $.13^{* *}$ \\
\hline $\begin{array}{l}\text { Emotional well- } \\
\text { being }\end{array}$ & & & & & $1.83(1.60)$ & $.51^{\star \star \star}$ & $.28^{\star \star \star}$ \\
\hline Life satisfaction & & & & & & $3.40(0.78)$ & $.33^{* \star \star}$ \\
\hline $\begin{array}{l}\text { Social } \\
\text { integration }\end{array}$ & & & & & & & $3.42(0.62)$ \\
\hline
\end{tabular}

\section{Data Analysis Strategies}

$\mathrm{H} 1$ was tested through the simple interaction model (model 1), whereas $\mathrm{H} 2$ was tested through the three-way interaction model (model 3), using Hayes' (2017) PROCESS macro for bias-corrected bootstrapping with 5,000 resamples. Public interactions and the two types of self-network discrepancy were standardized, and age was only standardized when $\mathrm{H} 2$ was tested. If a significant two-way interaction effect emerged, further analysis was conducted to compare the relationship between public interactions and emotional well-being between the high (1 standard deviation above the standardized mean) and low (1 standard deviation below the standardized mean) levels of perceived educational and social class self-network discrepancy, respectively. If a significant three-way interaction effect emerged, further analysis was conducted to demonstrate how the interaction effect between public interactions and perceived self-network discrepancy varied across older ( 1 standard deviation above the standardized mean) and younger participants ( 1 standard deviation below the standardized mean). The output of PROCESS provides unstandardized coefficients of each predictor and $R^{2}$ of the model, rather than standardized coefficients and adjusted $R^{2}$.

\section{Results}

\section{H1}

We first tested the possible moderating role of perceived educational self-network discrepancy. The model was significant, $R^{2}=.31, F(12,448)=16.82, p<.001$. The interaction effect between public interactions and perceived educational self-network discrepancy was significant $(B=-0.18, p<.02$, Table 2$)$. Further, engaging in public interactions only predicted emotional well-being significantly when participants reported a high level of perceived educational self-network discrepancy $(B=-0.33, p<.01)$ but no significant relationship was found for a low level of perceived educational self-network discrepancy $(p=.79$, Figure 1). Additionally, life satisfaction $(B=1.00, p<$ .001 ) and social integration $(B=0.38, p<.01)$ predicted emotional well-being positively. None of the other variables exhibited a significant relationship with emotional well-being.

Next, we tested if perceived social class self-network discrepancy would moderate the relationship between public interactions and emotional well-being. The model was significant, $R^{2}=.31, F(12,443)=16.20, p<.001$. The interaction effect between public interactions and perceived social class self-network discrepancy was not 
significant $(p=.17)$. Perceived social class self-network discrepancy predicted emotional well-being negatively $(B=$ $-0.17, p<.02$, Table 2). Life satisfaction $(B=1.00, p<.001)$ and social integration $(B=0.35, p<.01)$ remained a positive relationship with emotional well-being. None of the other variables exhibited a significant relationship with emotional well-being. Taken together, $\mathrm{H} 1$ received partial support for perceived educational self-network discrepancy but was rejected for perceived social class self-network discrepancy.

Figure 1. Two-Way Interaction Between Public Interactions and Perceived Educational Self-Network Discrepancy on Emotional WellBeing.

\section{6}

2.4

2.2

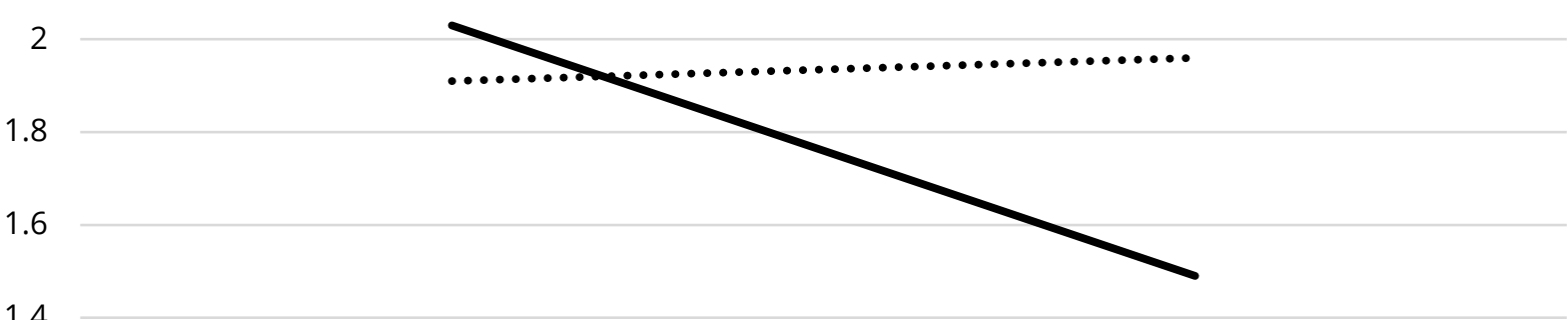

low public interactions

high public interactions

..... low perceived educational self-network discrepancy

high perceived educational self-network discrepancy

Table 2. Regressing Two-Way Interactions on Emotional Well-Being.

\begin{tabular}{llll}
\hline & $B$ & & \multicolumn{1}{c}{$B$} \\
\hline Gender & -0.05 & Gender & -0.05 \\
Age & 0.002 & Age & 0.002 \\
Education & -0.05 & Education & -0.04 \\
Income & -0.02 & Income & -0.02 \\
Retirement status & 0.23 & Retirement status & 0.24 \\
Co-living status & 0.07 & Co-living status & 0.07 \\
Network size & 0.00 & Network size & $<0.01$ \\
Life satisfaction & $1.00^{* * *}$ & Life satisfaction & $1.00^{* * *}$ \\
Social integration & $0.38^{* *}$ & Social integration & $0.35^{* *}$ \\
Public interactions & -0.15 & Public interactions & -0.14 \\
Perceived educational self-network & -0.09 & Perceived social class self-network \\
discrepancy & & discrepancy & $-0.17^{* *}$ \\
Public interactions * perceived & $-0.18^{*}$ & Public interactions * perceived social & -0.09 \\
educational self-network discrepancy & $.31^{* * *}$, & class self-network discrepancy & $R^{2}, F$
\end{tabular}

Note. ${ }^{* * *} p<.001,{ }^{* *} p<.01,{ }^{*} p<.05$. Gender: 0 = male, $1=$ female; Co-living status: $0=$ not live with children, $1=$ live with children; Retirement status: $0=$ non-retired, $1=$ retired.

\section{$\mathrm{H} 2$}

First, the model with perceived educational self-network discrepancy was significant, $R^{2}=.32, F(15,445)=14.12, p$ $<.001$. The three-way interaction effect was significant ( $B=-0.03, p<.03$, Table 3 ). The two-way interaction effect between public interactions and perceived educational self-network discrepancy was significant for older participants $(B=-0.37, p<.001)$ but not significant for younger participants $(p=.94)$. Specifically, among older participants, the negative relationship between public interactions and emotional well-being was only significant for high levels of perceived educational self-network discrepancy $(B=-0.60, p<.001$, Figure 2$)$. For younger 
participants, the relationship between public interactions and emotional well-being was nonsignificant across all levels of perceived educational self-network discrepancy. Again, life satisfaction $(B=1.02, p<.001)$ and social integration $(B=0.38, p<.001)$ predicted emotional well-being positively. The simple interaction effect between public interactions and perceived educational self-network discrepancy remained significant $(B=-0.19, p<.02)$, after all the other interaction effects were controlled. None of the other variables exhibited a significant relationship with emotional well-being.

Table 3. Regressing Three-Way Interactions on Emotional Well-Being.

\begin{tabular}{|c|c|c|c|}
\hline & $B$ & & $B$ \\
\hline Gender & -0.06 & Gender & -0.06 \\
\hline Education & -0.05 & Education & -0.05 \\
\hline Income & -0.02 & Income & -0.02 \\
\hline Retirement status & 0.23 & Retirement status & 0.24 \\
\hline Co-living status & 0.06 & Co-living status & 0.03 \\
\hline Network size & -0.00 & Network size & $<0.01$ \\
\hline Life satisfaction & $1.02^{* \star *}$ & Life satisfaction & $1.01^{* * *}$ \\
\hline Social integration & $0.38^{* * *}$ & Social integration & $0.36^{* *}$ \\
\hline Public interactions & -0.15 & Public interactions & -0.15 \\
\hline $\begin{array}{l}\text { Perceived educational self-network } \\
\text { discrepancy }\end{array}$ & -0.07 & $\begin{array}{l}\text { Perceived social class self-network } \\
\text { discrepancy }\end{array}$ & $-0.15^{*}$ \\
\hline $\begin{array}{l}\text { Public interactions * perceived } \\
\text { educational self-network discrepancy }\end{array}$ & $-0.19^{*}$ & $\begin{array}{l}\text { Public interactions * perceived social } \\
\text { class self-network discrepancy }\end{array}$ & -0.07 \\
\hline Age & 0.005 & Age & 0.003 \\
\hline Public interactions * age & -0.01 & Public interactions * age & -0.01 \\
\hline $\begin{array}{l}\text { Perceived educational self-network } \\
\text { discrepancy * age }\end{array}$ & 0.02 & $\begin{array}{l}\text { Perceived social class self-network } \\
\text { discrepancy * age }\end{array}$ & 0.01 \\
\hline $\begin{array}{l}\text { Public interactions * perceived } \\
\text { educational self-network discrepancy } \\
\text { * age }\end{array}$ & $-0.03^{*}$ & $\begin{array}{l}\text { Public interactions * perceived social } \\
\text { class self-network discrepancy * age }\end{array}$ & $-0.02^{*}$ \\
\hline$R^{2}, F$ & $\begin{array}{c}.32^{* \star *}, \\
F(15,445)=14.12\end{array}$ & $R^{2}, F$ & $\begin{array}{c}.31^{* \star *}, \\
F(15,440)=13.40\end{array}$ \\
\hline
\end{tabular}

Note. ${ }^{* * *} p<.001,{ }^{* *} p<.01,{ }^{*} p<.05$. Gender: $0=$ male, $1=$ female; Co-living status: 0 = not live with children, $1=$ live with children;

Retirement status: $0=$ non-retired, $1=$ retired.

Finally, the model predicting the three-way interaction effect between public interactions, perceived social class self-network discrepancy, and retirement status on emotional well-being was also significant, $R^{2}=.31, F(15,440)=$ $13.35, p<.001$. The three-way interaction effect was significant $(B=-0.02, p<.05$, Table 3 ). Again, the interaction effect between public interactions and perceived social class self-network discrepancy on emotional well-being was significant only for older participants $(B=-0.22, p<.02)$. For older participants, the relationship between public interactions and emotional well-being was only significant when perceived social class self-network discrepancy was at a high level $(B=-0.44, p<.01$; Figure 3$)$. In contrast, among younger participants, the relationship between public interactions and emotional well-being was nonsignificant across all levels of perceived social class selfnetwork discrepancy. Life satisfaction $(B=1.01, p<.001)$ and social integration $(B=0.36, p<.01)$ remained a positive relationship with emotional well-being. The simple interaction effect between public interactions and perceived social class self-network discrepancy was still not significant $(p=.27)$, and perceived social class selfnetwork discrepancy exhibited a negative relationship with emotional well-being $(B=-0.16, p<.02)$. Thus, $\mathrm{H} 2$ received partial support, as the two-way interaction effect on emotional well-being among older versus younger participants was not consistent with our prediction. 
Figure 2. Three-Way Interaction Between Public Interactions, Perceived Educational Self-Network Discrepancy, and Age on Emotional Well-Being.

younger (low age)

2.6

2.4

2.2

2

1.8

1.6

1.4

older (high age)

2.2

2

1.8

1.6

1.4

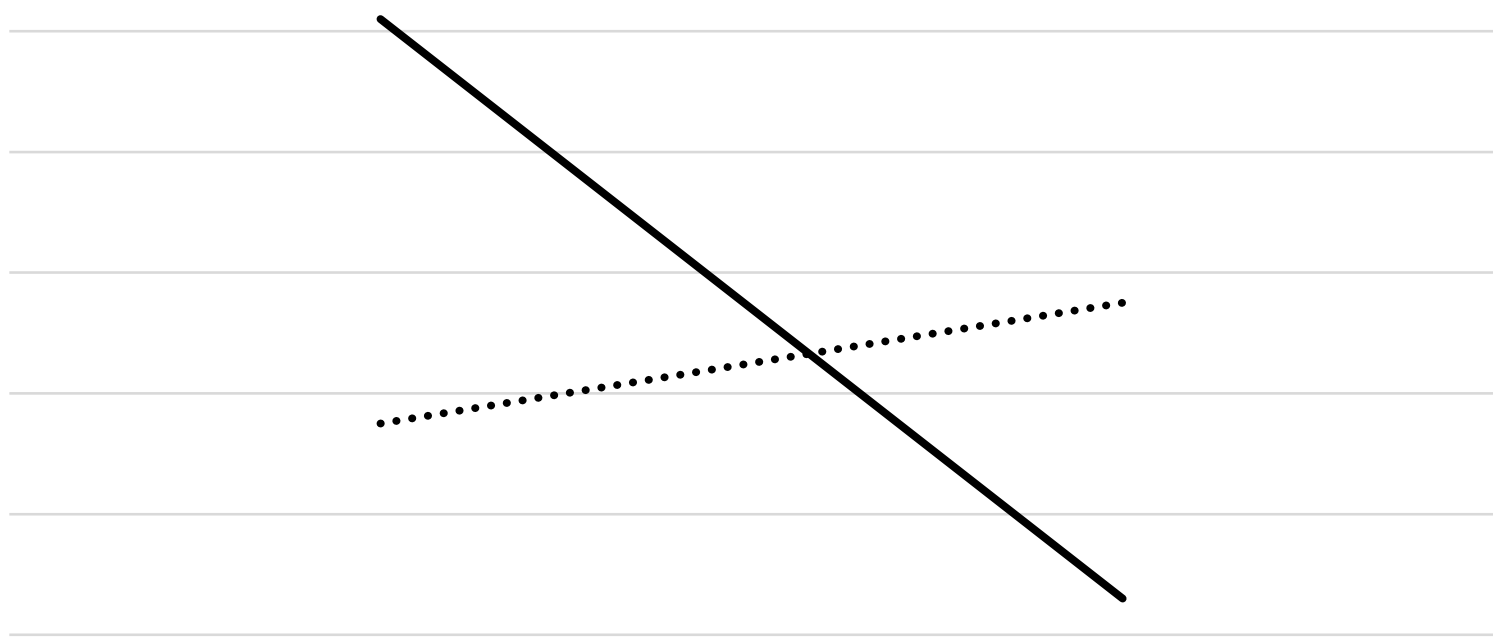

..... low perceived educational self-network discrepancy

high perceived educational self-network discrepancy 
Figure 3. Three-Way Interaction Between Public Interactions, Perceived Social Class Self-Network Discrepancy, and Age on Emotional Well-Being.

younger (low age)

2.2

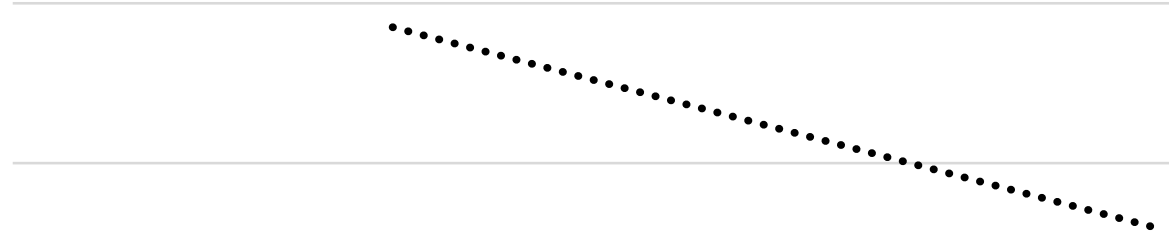

1.8

1.6

1.4

low public interactions

high public interactions

..... low perceived social class self-network discrepancy

high perceived social class self-network discrepancy

older (high age)

2.6

2.4

2.2

2

1.8

1.6

1.4

low public interactions

high public interactions

...... low perceived social class self-network discrepancy

high perceived social class self-network discrepancy

\section{Discussion}

The present study examines how one type of communication activity via an SNS popular in China influences the emotional well-being of an understudied population. Our study extends previous research on SNSs and well-being 
to a non-western SNS and a nontraditional population and provides empirical evidence on the scholarship on masspersonal communication. Furthermore, our investigation highlights the important roles that perceived selfnetwork discrepancy and age play in individuals' emotional well-being. These findings develop the literature on SST, the impact of SNSs on well-being, and masspersonal communication.

\section{Major Findings}

Our findings first reveal that perceived educational self-network discrepancy moderated the relationship between public interactions and emotional well-being of Chinese seniors and emerging seniors. Specifically, engaging in public interactions predicted their emotional well-being negatively when their WeChat network had a high level of perceived educational self-network discrepancy, whereas no significant effect was found when their educational level was perceived similarly to their WeChat contacts'. When individuals of different educational levels are offered equal access to one SNS post, they may provide different interpretations of the post because of their divergent values. Consequently, Chinese seniors and emerging seniors perceiving they differed from most of their WeChat members in terms of educational levels are more likely exposed to opinions that they disapprove and challenged by their WeChat contacts. These experiences can lower their emotional well-being.

One unexpected finding was that even when individuals perceived to share similar educational background with most of their WeChat members, engaging in public interactions did not exhibit a significant relationship with their emotional well-being. This might be because these individuals expect to receive agreements from their WeChat contacts. In other words, they might take it for granted when they receive endorsements from their SNS contacts. Hence, engaging in public interactions with a network of low self-network discrepancy might not influence their emotional well-being.

It is important to note that the moderation effect we found was built on an assumption that Chinese seniors and emerging seniors do not manage the boundary of their public interactions on WeChat. To the best of our knowledge, no research has been conducted to test this assumption, except in the U.S. (Wisniewski et al., 2014). Therefore, whether individuals employ boundary management strategies when they engage in public interactions may function as another moderator in the relationship between public interactions and emotional well-being, which future research should test.

Next, we did not find a significant moderation effect of perceived social class self-network discrepancy on the relationship between public interactions and emotional well-being. Instead, perceived social class self-network discrepancy predicted emotional well-being negatively. This might be because social class is compounded with education. Therefore, compared to perceived educational self-network discrepancy, perceived social class selfnetwork discrepancy can be more strongly related to value divergence, which predicted overall emotional wellbeing rather than conditionally.

In addition to these two-way interactions, we found that public interactions, perceived self-network discrepancy, and age exhibited a three-way interaction effect on emotional well-being. Specifically, engaging in public interactions with a network of high levels of perceived self-network discrepancy only lowered emotional well-being among older participants. This is opposite to our hypotheses and SST. One possible explanation is that previous SST research was conducted in offline contexts such as relational communication (Carstensen et al., 1995; Carstensen et al., 2000; Gross et al., 1997; Levenson et al., 1993), where older individuals have more knowledge and experiences about how to manage negative emotions. However, given that seniors and emerging seniors are usually digitally disadvantaged (Loges \& Jung, 2001), WeChat may still be relatively new to them. Even within this population, empirical evidence about digital divide was found such that older seniors were less digitally savvy compared to their younger counterparts (Friemel, 2016). Therefore, older participants may not be as familiar with WeChat as their younger counterparts, and thereby may be unable to regulate negative emotions derived from social interactions through SNSs.

This speculation provides a possible direction for SST research. As reviewed earlier, SST suggests that differences in one's negative emotion across age groups result from their different motivations for emotion management (Carstensen, 2006). However, our finding suggests that these differences may result from their abilities for emotion regulation. Future research can compare these two explanations. 


\section{Theoretical Implications}

Our investigation provides important implications for research on SNSs and well-being. First, the present study focuses exclusively on public interactions, rather than the overall usage of SNSs on well-being as most previous research. We call for this approach because it could provide more nuanced knowledge about how SNSs affect well-being, which can help the public to develop better understanding of SNS effects.

In addition, previous research shows that public interactions via SNSs could enhance users' well-being at least temporarily (Bazarova et al., 2015; Bayer et al., 2018), especially when these interactions were positively valenced (M. Choi \& Toma, 2014). However, our findings show that public interactions could reduce the emotional wellbeing of Chinese seniors and emerging seniors when their background was perceived to deviate from most of their WeChat contacts, whereas the same behavior did not affect their emotional well-being when their backgrounds were perceived similar. Although individuals do not usually provide negative feedback publicly via SNSs, they might express their disapproval through other channels such as offline interactions (Pearce \& Vitak, 2016). Hence, one possible reason why the present study found different results compared to those studies mentioned above is that we took our participants' reflection on their cross-cutting communication into consideration, which is indicated by their perception of self-network discrepancy. This suggests that future research on masspersonal communication via SNSs may need to consider the composition of one's SNS network and the quality of one's interactions with them.

\section{Practical Implications}

Our findings suggest that boundary management is critical to the quality of public interactions via SNSs and users' level of emotional well-being. Therefore, WeChat should develop features that help users compartmentalize their social contexts more easily. Currently WeChat allows users to place their contacts into different groups and block certain groups and individuals from viewing public WeChat posts. In the future, WeChat can promote these features by reminding users to set up privacy boundary for every new contact. In addition, WeChat can also ask users whether they want to share a post to their entire network before it is displayed and use algorithms to block certain contacts' posts from users' Moments.

\section{Limitations and Future Directions}

Although this study provides important theoretical and practical implications, we acknowledge the following limitations and call for further investigations to address them. First, we used a snowball sample because the number of senior WeChat users was still relatively small (Hersey, 2017). Thus, snowball sampling is appropriate to reach this population. Second, our sample is biased towards WeChat users with higher education and higher income. Compared to the national population, our participants were exceptionally better educated and reported higher income ${ }^{3}$. This might make our participants more digitally savvy. Hence, our participants might have better knowledge of WeChat usage, for instance, how to block certain contacts from viewing their public interactions. Thus, our participants might have reported a higher level of emotional well-being than the general population in China. Future research can try to minimize this bias through random sampling techniques.

Next, the cross-sectional nature of this study means that making causal claims is impossible. Additionally, our measure of emotional well-being only lasted one week and included four items. Previous research on the emotional well-being of seniors used the same time range and instrument (N. G. Choi et al., 2014). Nevertheless, future research can use the experience sampling method and more valid scales.

While nine control variables were included in our model, there could be other control variables which future research could consider. Examples of these control variables include SNS/Internet experience and personality.

Moreover, this study was conducted in a Chinese sample, which limits the generalizability of our findings. Future research should replicate our study with a different SNS platform and a different population. Cross-cultural comparisons can provide insights into cultural differences in SNS effects. Future research can also try to replicate our findings in a general population by comparing the young and seniors. 
In addition, our measure of perceived self-network discrepancy has only one item. Although research shows that single-item measures perform similarly to multiple items in terms of reliability and validity when used appropriately (Bergkvist, 2015), a more valid measure is still recommended. Future research can also use network data to assess actual self-network discrepancy and compare with the current findings.

Finally, the present investigation focused on visibility, a key affordance of SNSs, and examined its effect on emotional well-being. Future research can take a different approach to study what factors contribute to the design of technologies. Davis (2020) argued that technological affordance is not solely determined by individual-level factors. Instead, institutional, economic, societal, and cultural powers are intertwined to influence the design of technologies (Davis, 2020). Future research can take advantage of this perspective to investigate, for example, how users' individual needs and cultural legitimacy shape the design of SNS features.

\section{Conclusion}

As China and the entire world have become an aging society, the present study provides critical implications about how SNS use may affect well-being. Our investigation explicates the mechanism by which public interactions, an example of masspersonal communication, interact with perceived self-network discrepancy and age to predict emotional well-being, thereby offering theoretical implications on SNSs and well-being.

\section{Footnotes}

1. We use social networking service rather than social network site, following the recommendation by Y. Zhang and Leung (2014). Social network sites, as boyd and Ellison (2007) defined, refer to "web-based services" (p. 210). However, many social networking services are now available through smartphones, and WeChat Moments are only available via smartphones. We thus use social networking service to refer to a wider range of social networking platforms.

2. WeChat users cannot view or engage in any form of communication with other users until online connections are established. Thus, public interaction in the present study does not include open conversations accessible to everyone.

3. According to the most recent Chinese census available to the public (National Bureau of Statistics in China, 2020), the average monthly income of Chinese individuals was 2130.4 RMB, which is much lower than the monthly income level reported by the participants. In addition, about $13.9 \%$ of Chinese people had a college degree, $17.7 \%$ with a high school degree, $37.29 \%$ with a middle school degree, $0.064 \%$ with a master's degree or $\mathrm{PhD}$, and $30.39 \%$ with an elementary school degree or lower. This is also much lower than the current sample.

\section{References}

An, J., Kwak, H., Posegga, O., \& Jungherr, A. (2019). Political discussions in homogeneous and cross-cutting communication spaces. In Proceedings of the 13th International AAAI Conference on Web and Social Media (pp. 6879). AAAl. https://ojs.aaai.org//index.php/ICWSM/article/view/3210/3078/

Bail, C. A., Argyle, L. P., Brown, T. W., Bumpus, J. P., Chen, H., Hunzaker, M. B. F., Lee, J., Mann, M., Merhout, F., \& Volfovsky, A. (2018). Exposure to opposing views on social media can increase political polarization. PNAS, 115(37), 9216-9221. https://doi.org/10.1073/pnas.1804840115

Bayer, J., Ellison, N., Schoenebeck, S., Brady, E., \& Falk, E. B. (2018). Facebook in context(s): Measuring emotional responses across time and space. New Media \& Society, 20(3), 1047-1067.

https://doi.org/10.1177/1461444816681522

Bazarova, N. N., Choi, Y. H., Sosik, V. S., Cosley, D., \& Whitlock, J. (2015). Social sharing of emotions on Facebook: Channel differences, satisfaction, and replies. In Proceedings of the 18th ACM Conference on Computer Supported Cooperative Work \& Social Computing - CSCW' 15 (pp. 154-164). ACM. https://doi.org/10.1145/2675133.2675297 
Bergkvist, L. (2015). Appropriate use of single-item measures is here to stay. Marketing Letters, 26(3), 245-255. https://doi.org/10.1007/s11002-014-9325-y

Binder, J., Howes, A., \& Sutcliffe, A. (2009). The problem of conflicting social spheres: Effects of network structure on experienced tension in social network sites. In CHI '09: Proceedings of the SIGCHI Conference on Human Factors in Computing Systems (pp. 965-974). ACM. https://doi.org/10.1145/1518701.1518849

boyd, d. \& Ellison, N. B. (2007). Social network sites: Definition, history, and scholarship. Journal of ComputerMediated Communication, 13(1), 210-230. https://doi.10.1111/j.1083-6101.2007.00393.x

Brooks, S. (2015). Does personal social media usage affect efficiency and well-being? Computers in Human Behavior, 46, 26-37. https://doi.org/10.1016/j.chb.2014.12.053

Burke, M., Kraut, R., \& Marlow, C. (2011). Social capital on Facebook: Differentiating uses and users. In CHI '11: Proceedings of the SIGCHI Conference on Human Factors in Computing Systems (pp. 571-580). ACM. https://doi.org/10.1145/1978942.1979023

Carstensen, L. L. (2006). The influence of a sense of time on human development. Science, 312(5782), 1913-1915. https://doi.org/10.1126/science.1127488

Carstensen, L. L., Gottman, J. M., \& Levenson, R. W. (1995). Emotional behavior in long-term marriage. Psychology and Aging, 10(1), 140-149. https://doi.org/10.1037/0882-7974.10.1.140

Carstensen, L. L., Isaacowitz, D. M., \& Charles, S. T. (1999). Taking time seriously: A theory of socioemotional selectivity. American Psychologist, 54(3), 165-181. https://doi.org/10.1037/0003-066X.54.3.165

Carstensen, L. L., Pasupathi, M., Mayr, U., \& Nesselroade, J. R. (2000). Emotional experience in everyday life across the adult life span. Journal of Personality and Social Psychology, 79(4), 644-655.

https://doi.org/10.1037/0022-3514.79.4.644

Catapano, R., Tormala, Z. L., \& Rucker, D. D. (2019). Perspective taking and self-persuasion: Why "putting yourself in their shoes" reduces openness to attitude change. Psychological Science, 30(3), 424-435.

https://doi.org/10.1177/0956797618822697

Chang, P. M., Choi, Y. H., Bazarova, N. N., \& Löckenhoff, C. E. (2015). Age differences in online social networking: Extending socioemotional selectivity theory to social network sites. Journal of Broadcasting \& Electronic Media, 59(2), 221-239. https://doi.org/10.1080/08838151.2015.1029126

Choi, Y. H., \& Bazarova, N. N. (2015). Self-disclosure characteritics and motivations in social media: Extending the functional model to multiple social network sites. Human Communication Research, 41(4), 480-500.

https://doi.org/10.1111/hcre.12053

Choi, N. G., DiNitto, D. M., \& Kim, J. (2014). Discrepancy between chronological age and felt age: Age group difference in objective and subjective health as correlates. Journal of Aging and Health, 26(3), 458-473. https://doi.org/10.1177/0898264314523449

Choi, M., \& Toma, C. L. (2014). Social sharing through interpersonal media: Patterns and effects on emotional well-being. Computers in Human Behavior, 36, 530-541. https://doi.org/10.1016/j.chb.2014.04.026

Davis, J. L. (2020). How artifacts afford: The power and politics of everyday things. MIT Press. https://doi.org/10.7551/mitpress/11967.001.0001

Davis, J. L., \& Jurgenson, N. (2014). Context collapse: Theorizing context collusions and collisions. Information, Communication \& Society, 17(4), 476-485. https://doi.org/10.1080/1369118X.2014.888458 
Derlaga, V. J., \& Berg, J. H. (Eds.). (1987). Self-disclosure: Theory, research, and therapy. Plenum Press.

Diener, E., Emmons, R. A., Larsen, R. J., \& Griffin, S. (1985). The Satisfaction With Life Scale. Journal of Personality Assessment, 49(1), 71-75. https://doi.org/10.1207/s15327752jpa4901_13

Escobar-Viera, C. G., Shensa, A., Bowman, N. D., Sidani, J. E., Knight, J., James, A. E., \& Primack, B. A. (2018). Passive and active social media use and depressive symptoms among United States adults. Cyberpsychology, Behavior, and Social Networking, 21(7), 437-443. https://doi.org/10.1089/cyber.2017.0668

Fredrickson, B. L., \& Joiner, T. (2002). Positive emotions trigger upward spirals toward emotional well-being. Psychological Science, 13(2), 172-175. https://doi.org/10.1111/1467-9280.00431

Friemel, T. N. (2016). The digital divide has grown old: Determinants of a digital divide among seniors. New Media \& Society, 18(2), 313-331. https://doi.org/10.1177/1461444814538648

Gan, C. (2017). Understanding WeChat users' liking behavior: An empirical study in China. Computers in Human Behavior, 68, 30-39. https://doi.org/10.1016/j.chb.2016.11.002

Gross, J. J., Carstensen, L. L., Pasupathi, M., Tsai, J., Götestam Skorpen, C., \& Hsu, A. (1997). Emotion and aging: Experience, expression, and control. Psychology and Aging, 12(4), 590-599. https://doi.org/10.1037/0882-

7974.12.4.590

Guo, L. (2017). WeChat as a semipublic alternative sphere: Exploring the use of WeChat among Chinese older adults. International Journal of Communication, 11(2017), 408-428.

https://ijoc.org/index.php/ijoc/article/view/5537/1909

Hampton, K. N., Lee, C.-J., \& Her, E. J. (2011). How new media affords network diversity: Direct and mediated access to social capital through participation in local social settings. New Media \& Society, 13(7), 1031-1049. https://doi.org/10.1177/1461444810390342

Hayes, A. (2017). Introduction to mediation, moderation, and conditional process analysis: A regression-based approach (2nd ed.). Guilford Press.

Hersey, F. (2017, November 10). WeChat becomes "a lifestyle" as senior users, calls, and payments all see large increases. Technode. http://www.sohu.com/a/203631851_465957

Jiang, S. (2017). Pathway linking patient-centered communication to emotional well-being: Taking into account patient satisfaction and emotion management. Journal of Health Communication, 22(3), 234-242.

https://doi.org/10.1080/10810730.2016.1276986

John, N. A., \& Dvir-Gvirsman, S. (2015). "I don't like you any more": Facebook unfriending by Israelis during the Israel-Gaza conflict of 2014. Journal of Communication, 65(6), 953-974. https://doi.org/10.1111/jcom.12188

Jung, E. H., \& Sundar, S. S. (2016). Senior citizens on Facebook: How do they interact and why? Computers in Human Behavior, 61, 27-35. https://doi.org/10.1016/j.chb.2016.02.080

Kahneman, D., \& Deaton, A. (2010). High income improves evaluation of life but not emotional well-being. PNAS, 107(38), 16489-16493. https://doi.org/10.1073/pnas.1011492107

Kargbo, A. B. (2017, September 15). China demonstrates good examples of ethnic unity and equality. People's Daily. http://en.people.cn/n3/2017/0915/c90000-9269478.html 
Kohn, M. L. (1963). Social class and parent-child relationships: An interpretation. American Journal of Sociology, 68(4), 471-480. https://doi.org/10.1086/223403

Lee, J. K., Choi, J., Kim, C., \& Kim, Y. (2014). Social media, network heterogeneity, and opinion polarization. Journal of Communication, 64(4), 702-722. https://doi.org/10.1111/jcom.12077

Levenson, R. W., Carstensen, L. L., \& Gottman, J. M. (1993). Long-term marriage: Age, gender, and satisfaction. Psychology and Aging, 8(2), 301-313. https://doi.org/10.1037/0882-7974.8.2.301

Lien, C. H., \& Cao, Y. (2014). Examining WeChat users' motivations, trust, attitudes, and positive word-of-mouth: Evidence from China. Computers in Human Behavior, 41, 104-111. https://doi.org/10.1016/j.chb.2014.08.013

Litt, E. (2012). Knock. Knock. Who's there? The imagined audience. Journal of Broadcasting \& Electronic Media, 56(3), 330-345. https://doi.org/10.1080/08838151.2012.705195

Loges, W. E., \& Jung, J. Y. (2001). Exploring the digital divide: Internet connectedness and age. Communication Research, 28(4), 536-562. https://doi.org/10.1177/009365001028004007

Luo, M., \& Hancock, J. T. (2020). Self-disclosure and social media: Motivations, mechanisms and psychological well-being. Current Opinion in Psychology, 31, 110-115. https://doi.org/10.1016/j.copsyc.2019.08.019

Marino, C., Gini, G., Vieno, A., \& Spada, M. M. (2018). The associations between problematic Facebook use, psychological distress and well-being among adolescents and young adults: A systematic review and metaanalysis. Journal of Affective Disorders, 226, 274-281. https://doi.org/10.1016/j.jad.2017.10.007

Marwick, A. E., \& boyd, d. (2011). I tweet honestly, I tweet passionately: Twitter users, context collapse, and the imagined audience. New Media \& Society, 13(1), 114-133. https://doi.org/10.1177/1461444810365313

Ming, Y. (2021, March 17). China to raise retirement age to offset funding shortfall. VOA.

https://www.voanews.com/east-asia-pacific/voa-news-china/china-raise-retirement-age-offset-funding-shortfall

National Bureau of Statistics in China. (2020). 中国人口统计年鉴2020 [The 2020 Yearbook of Statistics in China]. http://www.stats.gov.cn/tjsj/ndsj/2020/indexch.htm

O'Sullivan, P. B. (1999). Bridging the mass-interpersonal divide: Synthesis scholarship in HCR. Human Communication Research, 25(4), 569-588. https://doi.org/10.1111/j.1468-2958.1999.tb00462.x

O'Sullivan, P. B., \& Carr, C. T. (2018). Masspersonal communication: A model bridging the mass-interpersonal divide. New Media \& Society, 20(3), 1161-1180. https://doi.org/10.1177/1461444816686104

Pearce, K. E., \& Vitak, J. (2016). Performing honor online: The affordances of social media for surveillance and impression management in an honor culture. New Media \& Society, 18(11), 2595-2612.

https://doi.org/10.1177/1461444815600279

Pfeil, U., Arjan, R., \& Zaphiris, P. (2009). Age differences in online social networking: A study of user profiles and the social capital divide among teenagers and older users in MySpace. Computers in Human Behavior, 25(3), 643654. https://doi.org/10.1016/j.chb.2008.08.015

Rui, J. R., \& Stefanone, M. A. (2013). Strategic image management online: Self-presentation, self-esteem, and social network perspectives. Information, Communication \& Society, 16(8), 1286-1305.

https://doi.org/10.1080/1369118x.2013.763834

Smith, A., \& Anderson, M. (2018). Social media use in 2018. Pew Research Center.

http://www. pewinternet.org/2018/03/01/social-media-use-in-2018/ 
Statista. (2019). Number of monthly active WeChat users from 2nd quarter 2012 to 2nd quarter 2019 (in millions). https://www.statista.com/statistics/255778/number-of-active-wechat-messenger-accounts/

Taber, K. S. (2018). The use of Cronbach's alpha when developing and reporting research instruments in science education. Research in Science Education, 48(6), 1273-1296. https://doi.org/10.1007/s11165-016-9602-2

Tromholt, M. (2016). The Facebook experiment: Quitting Facebook leads to higher levels of well-being. Cyberpsychology, Behavior, and Social Networking, 19(11), 661-666. https://doi.org/10.1089/cyber.2016.0259

Ursachi, G., Horodnic, I. A., \& Zait, A. (2015). How reliable are measurement scales? External factors with indirect influence on reliability estimators. Procedia Economics and Finance, 20,679-686. https://doi.org/10.1016/s22125671(15)00123-9

Utz, S., \& Breuer, J. (2017). The relationship between use of social network sites, online social support, and wellbeing: Results from a six-wave longitudinal study. Journal of Media Psychology, 29(3), 115-125. https://doi.org/10.1027/1864-1105/a000222

Walden, J. A. (2016). Integrating social media into the workplace: A study of shifting technology use repertoires. Journal of Broadcasting \& Electronic Media, 60(2), 347-363. https://doi.org/10.1080/08838151.2016.1164163

Wei, R., Huang, J., \& Zheng, P. (2018). Use of mobile social apps for public communication in China: Gratifications as antecedents of reposting articles from WeChat public accounts. Mobile Media \& Communication, 6(1), 108-126. https://doi.org/10.1177/2050157917728100

Wen, Z., Geng, X., \& Ye, Y. (2016). Does the use of WeChat lead to subjective well-being? The effect of use intensity and motivations. Cyberpsychology, Behavior, and Social Networking, 19(10), 587-592. https://doi.org/10.1089/cyber.2016.0154

Wisniewski, P., Knijnenburg, B., \& Lipford, H. (2014). Profiling Facebook users' privacy behaviors [Paper presentation]. The SOUPS 2014 Workshop on Privacy Personas and Segmentation, Menlo Park, CA.

World Health Organization. (2018, February 5). Ageing and health. https://www.who.int/news-room/factsheets/detail/ageing-and-health

Xinhua. (2018, July 31). Chinese senior citizens become more active on WeChat: Report. China Daily. https://www.chinadaily.com.cn/a/201807/31/WS5b5ff474a31031a351e91359.html

Xu, W. W., Stefanone, M. A., Rui, J. R. (2013). The benefits and burdens of network diversity: Political engagement on social networking sites. First Monday, 18(9). https://doi.org/10.5210/fm.v18i9.4822

Zhang, L., \& Jung, E. H. (2019). WeChatting for health: An examination of the relationship between motivations and active engagement. Health Communication, 34(14), 1764-1774.

https://doi.org/10.1080/10410236.2018.1536942

Zhang, Y., \& Leung, L. (2014). A review of social networking service (SNS) research in communication journals from 2006 to 2011. New Media \& Society, 17(7), 1007-1024. https://doi.org/10.1177/1461444813520477 


\section{Correspondence to:}

Jian R. Rui

College of Journalism and Communication, South China University of Technology

382 Waihuan East Road

Guangzhou, 510006

China

Email: ruijian(at)scut.edu.cn

Editorial record: First submission received on September 9, 2020. Revisions received on January 2, 2021 and April 10, 2021. Accepted for publication on April 26, 2021.

Editor in charge: Lenka Dedkova

\section{About Authors}

Jian Raymond Rui (Ph.D., University at Buffalo, the State University of New York) is a professor at Department of New Media and Communication, South China University of Technology.

Xi Cui (Ph.D., Texas A\&M University) is an associate professor at Department of Communication, College of Charleston.

Qian Xu (Ph.D., Penn State University) is an associate professor at Department of Strategic Communications, Elon University.

Nan Yu (Ph.D., Penn State University) is an associate professor at Nicholson School of Media and Communication, University of Central Florida.

(C) Author(s). The articles in Cyberpsychology: Journal of Psychosocial Research on Cyberspace are open access articles licensed under the terms of the Creative Commons BY-NC-ND 4.0 International License which permits unrestricted, non-commercial use, distribution and reproduction in any medium, provided the work is properly cited. 